\title{
Local electron beam induced reduction and crystallization of amorphous titania films
}

\author{
Philippe Kern, ${ }^{\text {a) }}$ Christian Jäggi, Ivo Utke, Vinzenz Friedli, and Johann Michler \\ EMPA, Materials Science and Technology, Feuerwerkerstrasse 39, CH-3602 Thun, Switzerland
}

(Received 29 March 2006; accepted 2 June 2006; published online 10 July 2006)

\begin{abstract}
We report local electron beam induced reduction and crystallization of electrolytic amorphous $\mathrm{TiO}_{2}$ films on steel at $20 \mathrm{keV}$, varying beam currents from $10 \mathrm{nA}$ to $24 \mu \mathrm{A}$. In situ substrate temperature measurements and beam heating calculations demonstrate the formation of anatase (Raman) below $270{ }^{\circ} \mathrm{C}$, clearly beneath the crystallization temperature of nonirradiated films $\left(\approx 440^{\circ} \mathrm{C}\right)$. The evolution of the sample current was correlated to oxide reduction via electron stimulated desorption. Atomic force microscopy revealed well defined cavities with Gaussian shape. The $e$-beam sensitivity of amorphous $\mathrm{TiO}_{2}$ allows for patterning of macroscopic films, inducing local changes in oxidation state and phase. (C) 2006 American Institute of Physics. [DOI: 10.1063/1.2219398]
\end{abstract}

The unusual properties of titanium dioxide $\left(\mathrm{TiO}_{2}\right)$, such as its chemical and thermal stability, excellent optical transmittance in the visible and the near-IR range, high refractive index, high dielectric constant, $n$-type semiconducting properties, as well as its photocatalytic activity, make thin $\mathrm{TiO}_{2}$ films attractive for wide applications. ${ }^{1-6} \mathrm{TiO}_{2}$ exists in the crystalline phases anatase, rutile, and brookite as well as in amorphous state $\left(a-\mathrm{TiO}_{2}\right)$. Oxygen loss can lead to nonstoichiometric $\mathrm{TiO}_{2-x}, \mathrm{Ti}_{n} \mathrm{O}_{2 n-1}$ magneli phases, ${ }^{7}$ as well as $\mathrm{Ti}_{2} \mathrm{O}_{3}, \mathrm{Ti}_{3} \mathrm{O}_{4}$, and $\mathrm{TiO}$. Accordingly, the physical properties can drastically change. Changes in the oxidation state can be provoked by thermal annealing in UHV or in reductive environment, which usually creates small quantities of $\mathrm{Ti}^{3+} \cdot{ }^{8-10}$ Much larger quantities of mixed Ti oxidation states $\left(\mathrm{Ti}^{3+}\right.$, $\mathrm{Ti}^{2+}, \mathrm{Ti}^{+}$) are observed after $\mathrm{Ar}^{+}$bombardment. ${ }^{8,10}$

Le Mercier et al. ${ }^{11,12}$ reported a drop in the electrical resistance from $10^{9}$ to $10 \Omega \mathrm{cm}$ upon $335 \mathrm{~nm}$ laser irradiation of rutile pellets, due to the presence of $\mathrm{Ti}^{3+}$ and $\mathrm{Ti}^{2+}$ species. A significant increase of electrical conductivity was also observed after $\mathrm{Ar}, \mathrm{Sn}$, and $\mathrm{W}$ ion implantation into rutile. ${ }^{13}$ Low-density $\left(\mu \mathrm{A} / \mathrm{cm}^{2},<1 \mathrm{kV}\right)$ electron beams ${ }^{10}$ were found to create a controlled number of $\mathrm{Ti}^{3+}$ defects in $\mathrm{TiO}_{2}(110)$. Under transmission electron microscope (TEM) electron beam ( $e$-beam) irradiation conditions, McCartney et al. ${ }^{14,15}$ observed formation of epitaxial TiO at current densities between 5 and $50 \mathrm{~A} / \mathrm{cm}^{2}$ and reduction beyond the monoxide after exposure of rutile single crystal samples at extremely high current densities $\left(10^{3}-10^{4} \mathrm{~A} / \mathrm{cm}^{2}\right)$ at $100-400 \mathrm{kV}$. $\mathrm{TiO}_{2}$ anatase powder did not show any noticeable structural or electronic changes upon TEM irradiation at $200 \mathrm{kV}$ and $3 \mathrm{~A} / \mathrm{cm}^{2} .{ }^{16}$ TEM $e$-beam heating of anodic oxides on $\mathrm{Al}, \mathrm{Nb}, \mathrm{Ta}$, and $\mathrm{W}$ resulted in local crystallization of as-formed amorphous oxides, with exception of anodic $\mathrm{TiO}_{2}$, already crystalline after anodization. ${ }^{17}$ Recently, amorphous $\mathrm{ZrO}_{2},{ }^{18}$ has been $e$-beam crystallized in the TEM.

This letter reports the controlled local secondary electron microscope (SEM) $e$-beam reduction and crystallization of $a-\mathrm{TiO}_{2}$ thin films deposited on macroscopic steel substrates via an electrolytic route. ${ }^{19}$ In situ monitored sample current and global film temperature as well as the calculated temperature rise in the $e$-beam center are correlated to reduction

${ }^{a}$ Author to whom correspondence should be addressed; electronic mail: philippe.kern@empa.ch and crystallization phenomena characterized ex situ by Raman and atomic force microscopy (AFM) measurements.

Deposition and characterization of electrolytic $\mathrm{TiO}_{2}$ thin films on conductive substrates are described elsewhere. ${ }^{19}$ Asdeposited hydrated films on mirror polished AISI 316 steel disks ( $\phi$ of $15 \mathrm{~mm}$ and thickness of $1 \mathrm{~mm}$ ) were annealed at $200{ }^{\circ} \mathrm{C}$, well below the crystallization temperature of electrolytic $\mathrm{TiO}_{2}\left[440^{\circ} \mathrm{C}\right.$ (Ref. 20)], to form dense $a-\mathrm{TiO}_{2}$ films of ca. $100 \mathrm{~nm}$ thickness. $\mathrm{TiO}_{2}$ surfaces were $\mathrm{O}_{2}$ plasma cleaned prior to irradiation. $e$-beam irradiations were performed in a Zeiss DSM 962 SEM at $20 \mathrm{kV}$ with beam currents of $24 \mu \mathrm{A}, 250 \mathrm{nA}, 30 \mathrm{nA}$, and $10 \mathrm{nA}$ according to Fig. 1(a) and Table I. The samples were mounted on a heating stage (held at RT or $250^{\circ} \mathrm{C}$ ). A small $K$-type thermoelement was fixed in the center of the $\mathrm{TiO}_{2}$ surface using conductive silver, and the steel substrate was fixed to the sample stage in the same way. The sample stage was electrically isolated from the SEM stage holder to allow for sample current mea-

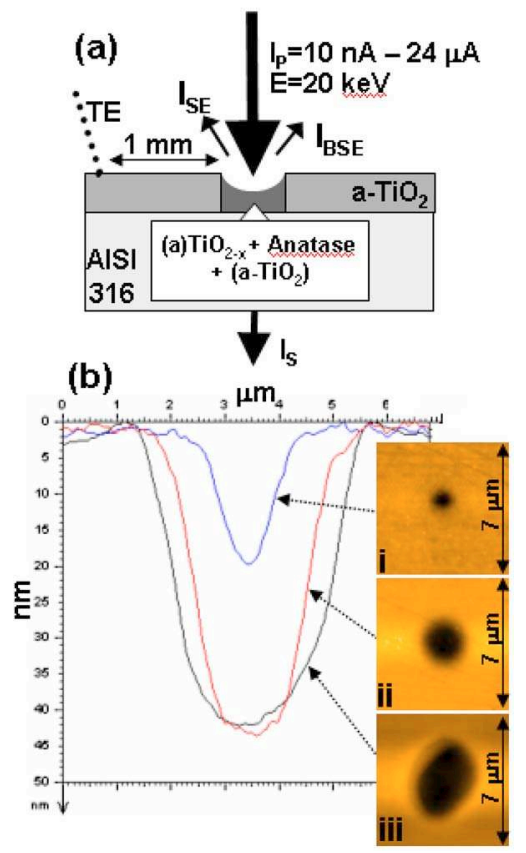

FIG. 1. (Color online) (a) Schematic representation of irradiation conditions. The sample is mounted on the heating stage. (b) AFM images and profiles of irradiated spots: (i) $10 \mathrm{nA} / 1 \mathrm{~s}$, (ii) $30 \mathrm{nA} / 3 \mathrm{~s}$, (iii) $250 \mathrm{nA} / 300 \mathrm{~s}$. 
TABLE I. Overview of irradiation conditions: $I_{P}=$ probe current, $t=$ irradiation time, $D=$ probe diameter, $J=$ current density, $T_{S}=$ measured global substrate/film temperature, $\Delta T=$ additional temperature rise in probe center, and $T_{\text {tot }}=$ total temperature in beam center.

\begin{tabular}{|c|c|c|c|c|c|c|c|c|c|}
\hline No. & $\begin{array}{l}\text { Dominating } \\
\text { mechanism }\end{array}$ & $I_{P}$ & $t(\mathrm{~s})$ & $D(\mu \mathrm{m})$ & $J\left(\mathrm{~A} \mathrm{~cm}^{-2}\right)$ & $T_{S}\left({ }^{\circ} \mathrm{C}\right)$ & $\Delta T\left({ }^{\circ} \mathrm{C}\right)$ & $T_{\text {tot }}\left({ }^{\circ} \mathrm{C}\right)$ & Phase \\
\hline 1 & Reduction & $\begin{array}{c}4.7 \mu \mathrm{A} \\
18.6 \mu \mathrm{A}\end{array}$ & $60 / 120$ & $\begin{array}{c}15 \\
210\end{array}$ & $\begin{array}{c}2.7 \\
0.05\end{array}$ & $120 / 125$ & $\begin{array}{l}89 \\
27\end{array}$ & $218 / 241$ & $\mathrm{TiO}_{2-x}$ \\
\hline 2 & Crystallization & $\begin{array}{c}4.7 \mu \mathrm{A} \\
18.6 \mu \mathrm{A}\end{array}$ & 600 & $\begin{array}{c}15 \\
210\end{array}$ & $\begin{array}{l}2.7 \\
0.05\end{array}$ & 220 & $\begin{array}{l}89 \\
27\end{array}$ & 336 & Anatase $+\mathrm{TiO}_{2-x}$ \\
\hline 3 & Crystallization & $\begin{array}{c}4.7 \mu \mathrm{A} \\
18.6 \mu \mathrm{A}\end{array}$ & 60 & $\begin{array}{c}15 \\
210\end{array}$ & $\begin{array}{l}2.7 \\
0.05\end{array}$ & 281 & $\begin{array}{l}89 \\
27\end{array}$ & 397 & Anatase $+\mathrm{TiO}_{2}$ \\
\hline 4 & Crystallization & $250 \mathrm{nA}$ & 600 & 4 & 2 & 250 & 17 & 267 & Anatase $+\mathrm{TiO}_{2-x}$ \\
\hline 5 & Reduction & $30 \mathrm{nA}$ & $1-10$ & 3 & 0.4 & 25 & 3 & 25 & $\mathrm{TiO}_{2-x}$ \\
\hline 6 & Reduction & $10 \mathrm{nA}$ & $1-10$ & 1.6 & 0.5 & 25 & 1 & 25 & $\mathrm{TiO}_{2-x}$ \\
\hline
\end{tabular}

surements (Keithley 6485 picoammeter). The irradiated zones were analyzed with Raman spectroscopy in backscattering geometry with a Renishaw Ramascope 2000 using a $633 \mathrm{~nm}$ HeNe laser and a spot size of $2-3 \mu \mathrm{m}$. AFM imaging (Topometrix Explorer) was performed in noncontact mode.

$e$-beam irradiation of a surface can result in radiation damage through atomic displacement, $e$-beam sputtering, $e$-beam heating, radiolysis, and electrostatic charging. ${ }^{21} \mathrm{Un}$ der the present conditions, radiation damage can uniquely occur from radiolysis and $e$-beam heating. For atomic displacement to happen, the maximum energy $E_{\max }$ transferable by an electron of mass $m_{e}\left(9.1 \times 10^{-28} \mathrm{~g} /\right.$ at. $)$ and kinetic energy $E$ to a nucleus of mass $m_{a}$ must be greater than the atomic displacement energy of the irradiated species. For nonrelativistic energies of scanning electron microscopes $E_{\max }=4 E\left(m_{e} / m_{a}\right) . \quad$ With $E=20 \mathrm{keV}, \quad m_{a}(\mathrm{O})=2.66$ $\times 10^{-23} \mathrm{~g} /$ at. and $m_{a}(\mathrm{Ti})=7.95 \times 10^{-23} \mathrm{~g} /$ at., and $E_{\max }$ $=2.7 \mathrm{eV}(\mathrm{O})$ and $0.9 \mathrm{eV}(\mathrm{Ti})$. The displacement energy for oxygen is much higher, $44-50 \mathrm{eV} .{ }^{22}$ Similarly, $e$-beam sputtering of surface atoms is unlikely at $20 \mathrm{keV}$. $^{29}$ According to Knotek and Feibelman, ${ }^{23}$ radiolysis of transition metal oxides can occur from the incident electrons creating an innershell vacancy on the metal site, being followed by interatomic Auger decay from the oxygen, resulting in desorption of neutral or even positively charged oxygen ions into the vacuum. ${ }^{24}$ Oxygen desorption stops as soon as the surface becomes sufficiently conductive (e.g., TiO) to stifle any further interatomic Auger decay.

The electron stimulated $\mathrm{O}$ desorption in $a-\mathrm{TiO}_{2}$ is directly evidenced by the volume loss shown from AFM profiling [Fig. 1(b)]. Well defined cavities with Gaussian shape are already observed after irradiations at $10 \mathrm{nA} / 1 \mathrm{~s}, 1.6 \mu \mathrm{m}$ in width and $17 \mathrm{~nm}$ in depth. Contrary to the observed pitting phenomena under TEM conditions, ${ }^{14,15}$ the shape of the cavities in Fig. 1(b) seems well defined, as long as no significant drift occurs during irradiation (some drift is visible after $250 \mathrm{nA} / 300 \mathrm{~s}$ ). It is interesting to notice that the depth of $40 \mathrm{~nm}$ in a $100 \mathrm{~nm}$ thick film after $30 \mathrm{nA} / 3 \mathrm{~s}$ and $250 \mathrm{nA} / 300 \mathrm{~s}$ irradiations is almost identical. This is good evidence for the discussed reduction mechanism, which stops as soon as the reduced film becomes sufficiently conductive. A color change from yellow to dark blue was observed in all irradiation conditions, most probably due to the formation of $\mathrm{Ti}_{2} \mathrm{O}_{3}$ in the outermost oxide layer. ${ }^{25}$ The full width at half maximum (FWHM) of the cavities in Fig. 1(b) were considered representative for the effective beam size at 10,30 , and $250 \mathrm{nA}$. The beam size without aperture at $I_{B}$ Downloaded 10 Aug 2006 to 152.88.240.168. Redistribution subje
$=24 \mu \mathrm{A}$ was determined using a vertical edged silicon. ${ }^{26}$ The beam current distribution has a large background of almost $2 \mathrm{~mm}$ in diameter. It could be well represented by an overlay of two Gaussian curves, a sharp central intensity of FWHM $=15.5 \mu \mathrm{m}\left(19.7 \%\right.$ of $\left.I_{B}\right)$ and a larger distribution with FWHM=209.5 $\mu \mathrm{m}\left(77.4 \%\right.$ of $\left.I_{B}\right)$. Probe diameters $D$ and the current densities $J$ for the present conditions are given in Table I.

In Fig. 2, the absolute value of the sample current $I_{S}$ upon irradiation at $I_{P}=30 \mathrm{nA}$ for $600 \mathrm{~s}$ steadily decreases from 15 to $14.7 \mathrm{nA}$. The sample current $I_{S}$ is connected to the beam current $I_{P}$, the current of the backscattered electrons $I_{\mathrm{BSE}}$, and the secondary electrons $I_{\mathrm{SE}}$ by $I_{S}=I_{P}-\left(I_{\mathrm{BSE}}\right.$ $\left.+I_{\mathrm{SE}}\right)$. Accordingly, the current decrease can be explained by an increase of $I_{\mathrm{BSE}}$ and/or $I_{\mathrm{SE}}$. Reduction and oxygen loss will increase the average atomic mass $Z$ in the irradiated area (Ti:47.88 and O:15.99). A maximum $\Delta Z$ of +5.3 would be expected $\left(\mathrm{TiO}_{2}-\mathrm{TiO}\right)$. Since the electron interaction volume is mostly situated in the bulk steel pellet (electron range about $1 \mu \mathrm{m}$ at $20 \mathrm{keV}$ ), the backscattered electron (BSE) generation is negligibly affected by a chemical transformation in the $100 \mathrm{~nm}$ thin oxide film. The secondary electron (SE) yield is known to increase with increasing $Z{ }^{27}$ To exclude any change of SE and BSE yields with temperature we irradiated the pure steel pellet and found no change in sample current. Thus we can conclude that the current decrease gives direct evidence of the ongoing oxide reduction.

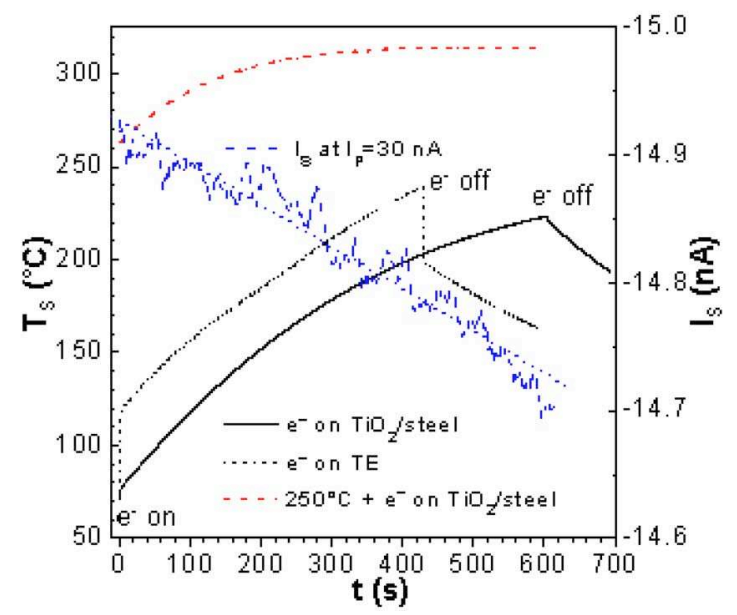

FIG. 2. (Color online) Evolution of global substrate/film temperature $T_{S}$ (left) with and without substrate preheating under $e$-beam irradiation at $24 \mu \mathrm{A} / 600 \mathrm{~s}$ (TE=thermoelement). Evolution of sample current $I_{S}$ (right) upon reduction during irradiation at $I_{P}=30 \mathrm{nA}$. The absolute value of the negative $I_{S}$ is plotted. 


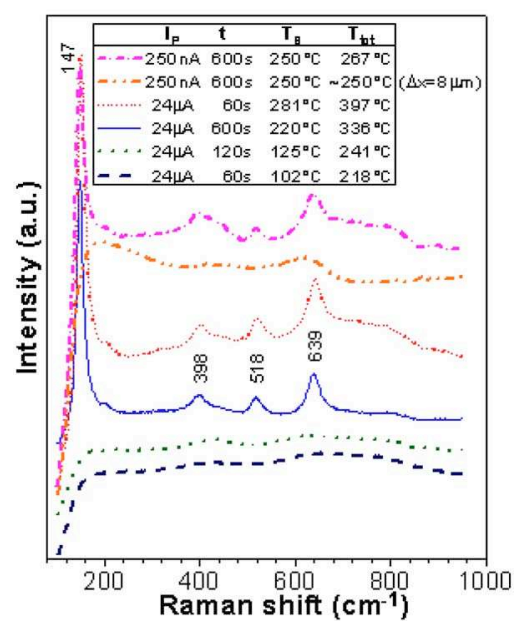

FIG. 3. (Color online) Laser Raman spectra of electrolytic $\mathrm{TiO}_{2}$ films after different $e$-beam irradiation conditions $\left(I_{P}=\right.$ probe current, $t=$ irradiation time, $T_{S}=$ measured global substrate/film temperature, and $T_{\text {tot }}=$ total temperature in beam center).

The measured global film/substrate temperature $T_{S}$ upon irradiation in Fig. 2 demonstrates that the $T_{S}$ without substrate preheating steadily increases from 70 to about $220{ }^{\circ} \mathrm{C}$ during irradiation at $24 \mu \mathrm{A} / 600 \mathrm{~s}$. The initial $T_{S}$ above RT is due to the slow cooling rate after an earlier irradiation at a different spot. The experiment was repeated while directly spotting on the thermoelement. With the exception of interference between beam current and thermoelement circuit, leading to an instantaneous reversible offset upon starting the irradiation, the $T_{S}$ follows exactly the same behavior. It was concluded that the irradiation results in a global heating of substrate and film. The same irradiation provokes a temperature rise from 250 to $315{ }^{\circ} \mathrm{C}$ when the substrate is preheated at $250^{\circ} \mathrm{C}$ [Fig. 3(b)]. For irradiations at $250 \mathrm{nA}$, only a very small $T_{S}$ rise of a few degrees was observed (not shown). The additional temperature rise $\Delta T$ above bulk substrate temperature in the center of a stationary electron beam with an acceleration voltage $U$ and a beam current $I$ can be estimated by

$$
\Delta T=\frac{3 U I_{P}(1-\eta)}{2 \pi \kappa\left(R_{E} / 2+D\right)},
$$

where $\eta$ is the percentage of backscattered electrons (Fe: $\eta$ $=0.29), R_{E}$ is the electron range $\left(\mathrm{Fe}: R_{E}=1.2 \mu \mathrm{m}\right.$ at $\left.20 \mathrm{kV}\right)$, $D$ is the probe diameter, and $\kappa$ is the thermal conductivity (steel: $\kappa=22 \mathrm{~W} \mathrm{~m}^{-1} \mathrm{~K}^{-1}$ and $\mathrm{TiO}_{2}: \kappa=11.7 \mathrm{~W} \mathrm{~m}^{-1} \mathrm{~K}^{-1}$ ). For $D \ll R_{E} / 2$, Eq. (1) reduces to the formula given by a derivation in Ref. 27. Since the micrometer-sized electron interaction volume is situated inside the steel pellet, the values of steel (iron) are used in Eq. (1). The calculated $\Delta T$ values and the total temperature $T_{\mathrm{tot}}=T_{s}+\Delta T$ in the irradiated zones are given in Table I for all conditions. For irradiation at $24 \mu \mathrm{A}$, $\Delta T$ was calculated as the sum of $\Delta T$ for both Gaussian intensity distributions. Raman spectra in Fig. 3 of the irradiated spots with and without substrate preheating show the typical signature of anatase ${ }^{28}$ after irradiation at $24 \mu \mathrm{A} / 600 \mathrm{~s}$, but does not indicate crystallization after 60 and $120 \mathrm{~s}$, where only an amorphous signal from $\mathrm{TiO}_{2-x}$ (including $\mathrm{Ti}_{2} \mathrm{O}_{3}$ ) and possibly remaining $a-\mathrm{TiO}_{2}$ is measured. With sample preheating at $250{ }^{\circ} \mathrm{C}$, a strong anatase signal is observed already after $60 \mathrm{~s}$. With preheating, local crystallization can also be induced at $250 \mathrm{nA} / 600 \mathrm{~s}$, which has not been obDownloaded 10 Aug 2006 to 152.88.240.168. Redistribution subject served without preheating within the investigated $3000 \mathrm{~s}$ of irradiation. Crystallization occurs very locally, as indicated by the amorphous signal obtained ca. $8 \mu \mathrm{m}$ away from the irradiation center. The presence of anatase in Fig. 3 is observed at $T_{\text {tot }}$ (Table I) considerably below the crystallization temperature $\left[440{ }^{\circ} \mathrm{C}\right.$ (Ref. 20)] of electrolytically deposited $a-\mathrm{TiO}_{2}$ films. In condition 4, Raman spectra showed anatase at $T_{\text {tot }}=267^{\circ} \mathrm{C}$. A change of crystallization kinetics as a result of radiation damage under TEM conditions has been proposed by Aladjem et al. ${ }^{17}$ without measuring beam heating. Roddatis et al. ${ }^{18}$ reported the crystallization of amorphous zirconia films kept at liquid helium temperature upon intense TEM irradiation. In the present study, crystallization of electrolytic $\mathrm{TiO}_{2}$ films on steel was possible below $270{ }^{\circ} \mathrm{C}$. We conclude that the decrease of the crystallization temperature of more than $170{ }^{\circ} \mathrm{C}$ is a result of the intense radiation damage.

In summary, we have evidenced the possibility of controlled local reduction (thickness decrease from 100 to $60 \mathrm{~nm}$ ) and crystallization of thin amorphous, $e$-beam sensitive $\mathrm{TiO}_{2}$ films on macroscopic well conductive substrates by $e$-beam irradiation under SEM conditions. Using intense electron beams, these phenomena are sufficiently rapid to allow for large area high resolution patterning of amorphous valve metal oxides.

${ }^{1}$ K. Bange, C. R. Ottermann, O. Anderson, U. Jeschkowski, M. Laube, and R. Feile, Thin Solid Films 197, 279 (1991).

${ }^{2}$ Y. Sawada and Y. Taga, Thin Solid Films 116, L55 (1984).

${ }^{3}$ M. R. Hoffmann, S. T. Martin, W. Choi, and D. W. Bahnemann, Chem. Rev. (Washington, D.C.) 95, 69 (1995).

${ }^{4}$ K. Katayama, K. Hasegawa, Y. Takahashi, and T. Akiba, Sens. Actuators, A A24, 55 (1990).

${ }^{5}$ K. L. Siefering and G. L. Griffin, J. Electrochem. Soc. 137, 1206 (1990).

${ }^{6}$ H. P. Maruska and A. K. Gosh, Sol. Energy Mater. 1, 237 (1979).

${ }^{7}$ A. Magneli, Acta Chem. Scand. (1947-1973) 2, 501 (1948).

${ }^{8}$ W. Gopel, J. A. Anderson, D. Frankel, M. Jaehnig, K. Phillips, J. A. Schafer, and G. Rocker, Surf. Sci. 139, 333 (1984).

${ }^{9}$ J. M. Pan, B. L. Maschhoff, U. Diebold, and T. E. Madey, J. Vac. Sci. Technol. A 10, 2470 (1992).

${ }^{10}$ L. Q. Wang, D. R. Baer, and M. H. Engelhard, Surf. Sci. 295, 320 (1994).

${ }^{11}$ T. Le Mercier, E. Bermejo, and M. Quarton, Mater. Sci. Eng., B 25, 92 (1994).

${ }^{12}$ T. Le Mercier, J. M. Mariot, F. Goubard, M. Quarton, M. F. Fontaine, and C. F. Hague, J. Phys. Chem. Solids 58, 679 (1997).

${ }^{13}$ R. Fromknecht, R. Auer, I. Khubeis, and O. Meyer, Nucl. Instrum. Methods Phys. Res. B 120, 252 (1996).

${ }^{14}$ M. R. McCartney, P. A. Crozier, J. K. Weiss, and D. J. Smith, Vacuum 42, 301 (1991)

${ }^{15}$ M. R. McCartney and D. J. Smith, Surf. Sci. 250, 169 (1991).

${ }^{16}$ D. S. Su, Anal. Bioanal. Chem. 374, 732 (2002).

${ }^{17}$ A. Aladjem, D. G. Brandon, J. Yahalom, and J. Zahavi, Electrochim. Acta 15, 663 (1970).

${ }^{18}$ V. V. Roddatis, D. S. Su, F. C. Jentoft, and R. Schlögl, Philos. Mag. A 82, 2825 (2002).

${ }^{19}$ P. Kern, P. Schwaller, and J. Michler, Thin Solid Films 494, 279 (2006).

${ }^{20}$ I. Zhitomirsky and L. Gal-Or, J. Eur. Ceram. Soc. 16, 819 (1996).

${ }^{21}$ R. F. Egerton, P. Li, and M. Malac, Micron 35, 399 (2004).

${ }^{22}$ G. P. Pells, Radiat. Eff. 64, 71 (1982).

${ }^{23}$ M. L. Knotek and P. J. Feibelman, Phys. Rev. Lett. 40, 964 (1978).

${ }^{24}$ M. L. Knotek and P. J. Feibelman, Surf. Sci. 90, 78 (1979).

${ }^{25}$ A. P. del Pino, J. M. Fernández-Pradas, P. Serra, and J. L. Morenza, Surf. Coat. Technol. 187, 6 (2004).

${ }^{26}$ S. A. Rishton, S. P. Beaumont, and C. D. W. Wilkinson, J. Phys. E 17, 296 (1984).

${ }^{27}$ L. Reimer, Scanning Electron Microscopy, 2nd ed. (Springer, Berlin, 1998), pp. 117 and 118.

${ }^{28}$ W. F. Zhang, Y. L. He, M. S. Zhang, Z. Yin, and Q. Chen, J. Phys. D 33, 912 (2000).

${ }^{29}$ R. F. Egerton, P. Li, and M. Malac, Micron 35, 401 (2004).

o AIP license or copyright, see http://apl.aip.org/apl/copyright.jsp 